\title{
Painful tic convulsive as manifestation of vertebrobasilar dolichoectasia
}

\section{Tique convulsivo doloroso como manifestacão de dolicoectasia vertebrobasilar}

Carlos Arteaga Rodriguez', Heraldo de Oliveira Mello Neto², Otto Jesus Hernandez Fustes³ ${ }^{3}$ Hélio Afonso Ghizoni Teive ${ }^{3}$

A 79-year-old man presented with a one-year history of intense, paroxysmal, left-sided facial pain (V2 and V3 trigeminal division), that felt like an electric shock for a duration of seconds, and four months of involuntary spasms of the left side of the face involving perioral and periocular muscles. An MRI with angiography showed a vertebrobasilar dolichoectasia causing compression of the left V,
VII and VIII cranial nerves (Figures $1 \mathrm{~A}$ and $\mathrm{B}$, and 2). The combined presentation of hemifacial spasm and ipsilateral trigeminal neuralgia is also known as painful tic convulsive, which is a rare condition commonly associated with vascular compression ${ }^{1,2,3,4}$. We report a case secondary to vertebrobasilar dolichoectasia.
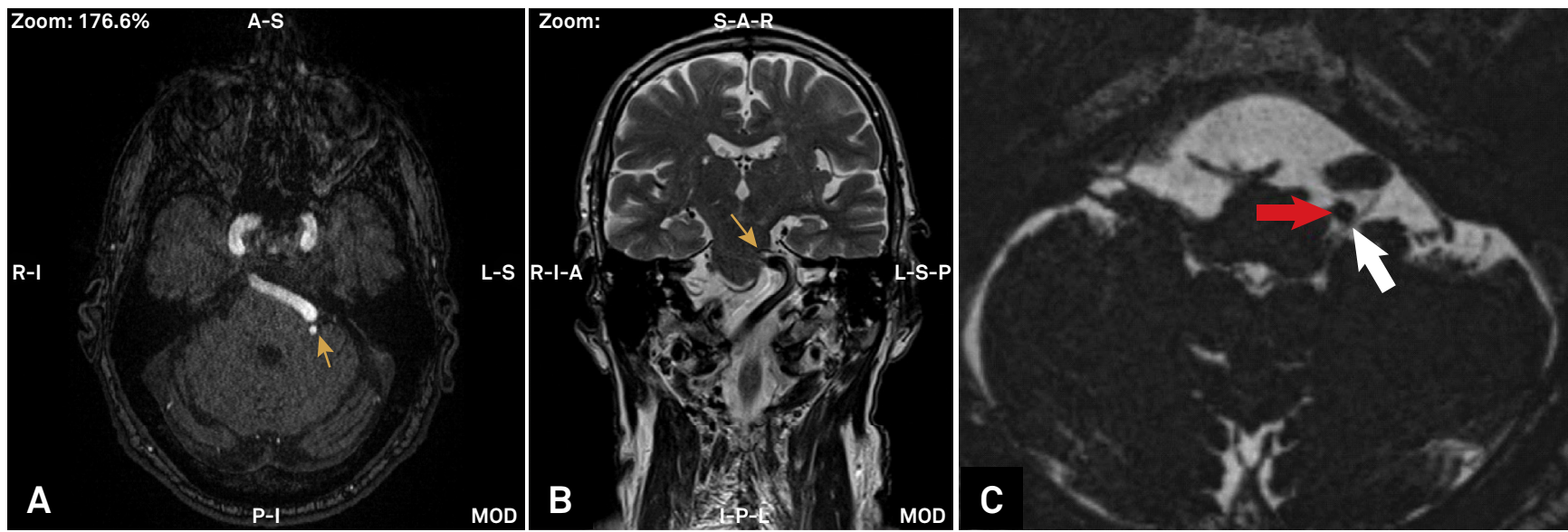

Figure 1. MRI: a) Time-of-flight axial image at the level of the cerebellopontine angle showing vascular compression of the left vertebral artery on the cisternal segment of the VII and VIII cranial nerves (yellow arrow); b) Coronal image in T2 shows tortuosity of the basilar artery dislocating superior to the cisternal segment of the $\mathrm{V}$ left cranial nerve (yellow arrow); c) Minimum intensity projection of axial constructive interference steady state imaging shows the segment $\mathrm{V} 4$ of the left vertebral artery (red arrow), displacing the proximal portion of the cisternal segment of the VII / VIII left cranial nerves (white arrow).

\footnotetext{
${ }^{1}$ Universidade Positivo, Curitiba, PR, Brasil;

${ }^{2} X$ Leme Diagnóstico por Imagem, Curitiba, PR, Brasil;

${ }^{3}$ Universidade Federal do Paraná, Hospital de Clínicas, Serviço de Neurologia, Curitiba, PR, Brasil.

Otto Jesus Hernandez Fustes iD https://orcid.org/0000-0003-0778-5376

Correspondence: Otto J. H. Fustes; Rua General Carneiro 181 / SAM 25; 80060-900 Curitiba PR, Brasil; E-mail: otto.fustes@hc.ufpr.br

Conflict of interest: There is no conflict of interest to declare.

Received 07 December 2018; Received in final form 22 January 2019; Accepted 01 February 2019.
} 


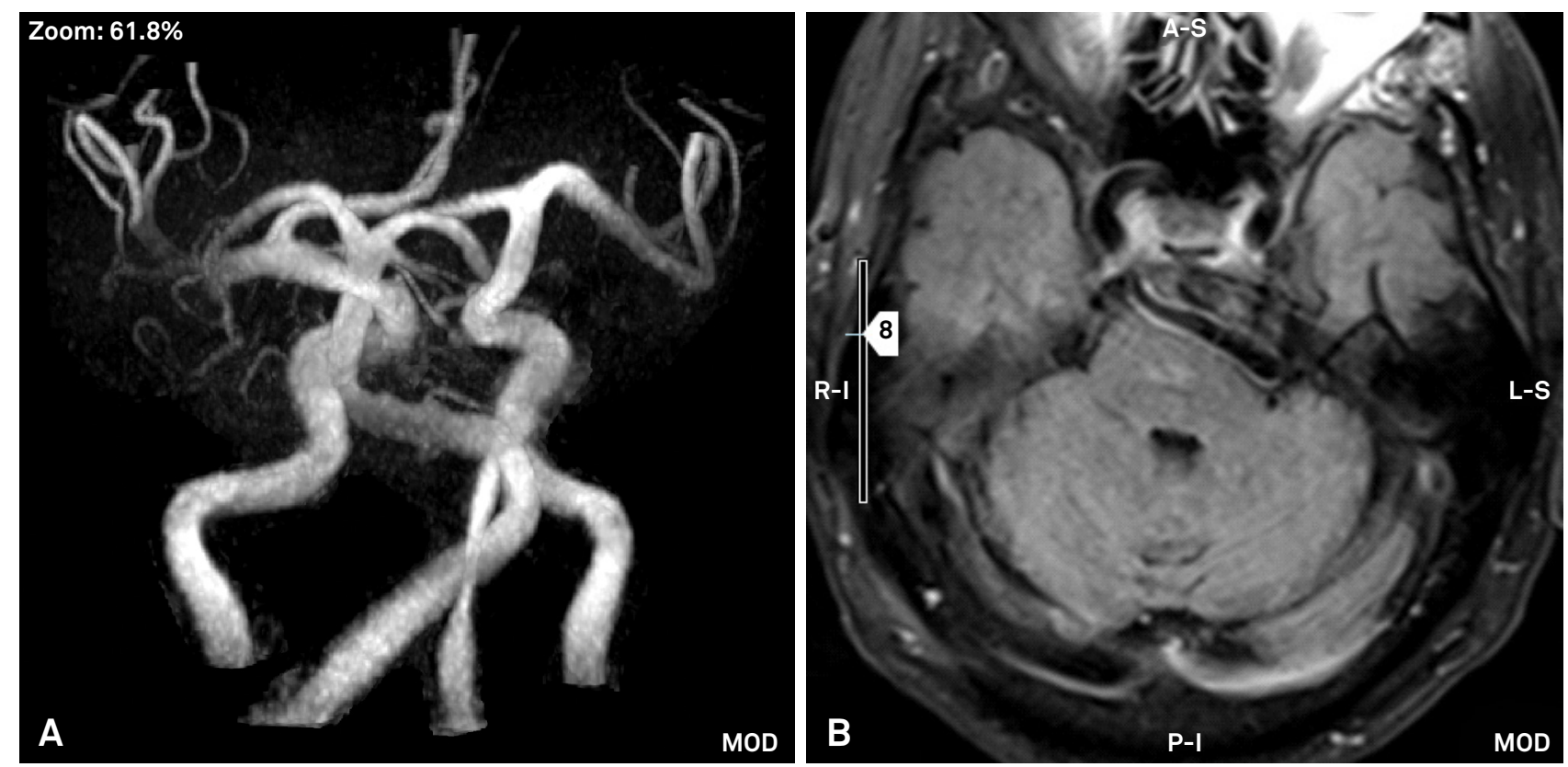

Figure 2. MRI. a) Left vertebrobasilar dolicoectasia with a diameter of $6 \mathrm{~mm}$; b) Axial FLAIR image shows vertebrobasilar dolichoectasia promoting rectification and compression on the left ventrolateral face of the pons.

\section{References}

1. Donahue JH, Ornan DA, Mukherjee S. Imaging of vascular compression syndromes. Radiol Clin North Am. 2017 Jan;55(1):123-38. https://doi.org/10.1016/j.rcl.2016.08.00

2. Moya-Martinez R, Cruz-Toro P, Junyent J, Domènech I.

Tic convulsivo doloroso como manifestación de dolicoectasia y aneurisma vertebrobasilar. Acta Otorrinolaringol Esp. 2015 Oct;66(5):296-8. https://doi.org/10.1016/j.otorri.2014.02.004
3. Kobata H, Kondo A, Iwasaki K, Nishioka T. Combined hyperactive dysfunction syndrome of the cranial nerves: trigeminal neuralgia, hemifacial spasm, and glossopharyngeal neuralgia: 11-year experience and review. Neurosurgery. 1998 Dec;43(6):1361-2. https://doi.org/10.1097/00006123-199812000-00052

4. Han IB, Chang JH, Chang JW, Huh R, Chung SS. Unusual causes and presentations of hemifacial spasm. Neurosurgery. 2009 Jul;65(1):130-7. https://doi.org/10.1227/01.NEU.0000348548.62440.42 